\title{
Reconstruction of the anterior skull base with radial forearm free tissue transfer: case series and literature review
}

\author{
Windy A. Olaya, Lauren T. Daly, Emily G. Clark, Thomas Scholz, Vincent Laurence, \\ Keyianoosh Z. Paydar, Garrett A. Wirth, Gregory R. D. Evans
}

Aesthetic and Plastic Surgery Institute, University of California Irvine, Orange, CA 92868, USA.

Address for correspondence: Dr. Windy A. Olaya, Aesthetic and Plastic Surgery Institute, University of California Irvine, 200 South Manchester, Suite 650, Orange, CA 92868, USA. E-mail: wolaya@uci.edu

\begin{abstract}
Aim: Reconstruction of the anterior skull base offers an especially complex challenge as the impermeable separation of the dural space and the upper aerodigestive tract must be maintained. We propose the use of the radial forearm free flaps (RFFF) as a superb method of re-establishing integrity in anterior skull base defects. Methods: Literature review and retrospective analysis of 4 single-institution cases of anterior skull base defects reconstructed with a RFFF. Data were collected on successful and unsuccessful defect repairs, complication rates, and length of hospitalization. Results: The indications for surgery were pneumocephalus, recurrent brain abscesses, recurrent frontal sinus mucoceles, and cerebrospinal fluid leak. Of the 4 cases, 1 was complicated by a small dehiscence of the craniotomy site, 1 developed infection, and 2 required further surgery. Conclusion: The use of RFFF is an excellent option for reconstruction of defects in the anterior skull base, especially those complicated by radiation, prior surgery, or infections. Patients with skull base defects are inherently at high risk for post-surgical complications. The RFFF transfers healthy, viable, well-vascularized tissue to prevent further infections and provides a reliable barrier between the dural and sinonasal spaces. This can reduce the need for repeat neurosurgical operations and hospitalizations.
\end{abstract}

Key words:

Aterior skull base; defect; reconstruction; plastic surgery; free flap; radial forearm free flap

\section{INTRODUCTION}

The use of free tissue transfer for reconstructing the anterior skull base has become a well-established treatment for the rehabilitation of patients with life-threatening and disfiguring defects resulting from craniofacial resections. Defects of the anterior skull base are intrinsically complex with an irregular serrated surface separating the dura from the sinonasal space, and are often complicated further by radiation, multiple prior surgical interventions, and repeat

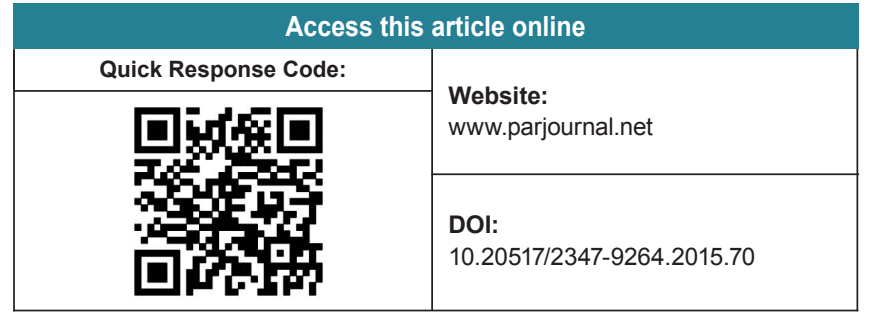

infections. ${ }^{[1-4]}$ Patients with these defects are generally quite ill with poor nutritional status and a weakened immune system. They are at risk for multiple life-threatening conditions including meningitis, encephalitis, brain abscess, persistent cerebrospinal fluid (CSF) leak, pneumocephalus, and even herniation of brain tissue. ${ }^{[1-3]}$ Thus it is paramount that reconstruction of anterior skull base defects be

This is an open access article distributed under the terms of the Creative Commons Attribution-NonCommercial-ShareAlike 3.0 License, which allows others to remix, tweak and build upon the work non-commercially, as long as the author is credited and the new creations are licensed under the identical terms.

For reprints contact: service@oaepublish.com

How to cite this article: Olaya WA, Daly LT, Clark EG, Scholz T, Laurence V, Paydar KZ, Wirth GA, Evans GRD. Reconstruction of the anterior skull base with radial forearm free tissue transfer: case series and literature review. Plast Aesthet Res 2016;3:47-51.

Received: 18-06-2015; Accepted: 04-12-2015 
complete, reliable, and reconstruct a "water tight" barrier between the intracranial cavity and the physiologically contaminated upper aerodigestive tract.

In 1966, Ketcham et al. ${ }^{[5]}$ first attempted the use of a split thickness skin graft to cover exposed dura in a patient who had undergone resection of a tumor located in the anterior skull base, but this procedure resulted in a persistent CSF leak. Since this time, many other surgical reconstructive methods have been utilized because surgeons realized the importance of using well-vascularized tissue in reconstructing a dural seal including regional flaps such as the temporalis, muscle pericranial grafts, and galea-frontalismyofascial flaps..$^{[6-8]}$ In cases where local flaps have already failed or are otherwise not possible due to destructed wound beds, the use of pedicled flaps such as the pectoralis major, sternocleidomastoid, trapezius, and latissimus dorsi have been popular. ${ }^{[6,9]}$ The drawbacks typically observed with these pedicled flaps are related to their distance limitations and bulkier size. The sternocleidomastoid flap is additionally challenging due to its segmental blood supply. ${ }^{[4]}$ The endoscopically performed pedicled nasoseptal flap is a newer method gaining popularity within the otolaryngology community. ${ }^{[10]}$ Weber et al. ${ }^{[11]}$ described success in using a variety of free tissue transfer for both skull base defects and craniofacial reconstruction with exposed dura for anterior, middle and posterior skull defects combined. Other novel efforts to repair these complex defects have been reported, including a sandwiched or folded free fasciocutaneous flap, and titanium mesh bolstered free tissue flaps. ${ }^{[12,13]}$

The last two decades have brought the increasing popularity of free tissue transfer for defects in this region. ${ }^{[14-16]}$ As noted by Neligan et al.. ${ }^{[9]}$ the use of distant free flaps is associated with a lower overall complication rate (33.5\%) than both local pedicled flaps (38.8\%), and regional flaps/grafts (75\%). Due to their exceptional vascularity, ability to fill irregular spaces with a thin but sturdy fascial layer, and overall decreased rate of complication, the authors hypothesized that the use of radial forearm free flaps (RFFF) for the reconstruction of especially complex anterior skull base defects would offer an ideal reconstructive option. The authors present a case series of four patients to have reconstruction of the anterior skull base with radial forearm free tissue transfer.

\section{METHODS}

Four patients presented to our institution with complex anterior skull base defects, complicated by infections, pneumocephalus, and CSF leaks. All four were treated with RFFF for closure of the communicating spaces. Retrospectively, the patient scenarios, surgical management, and outcomes were reviewed. Data collected included flap survival, complications requiring non-operative management, the need for reoperation, length of hospital stay, and donor site morbidity. Patient diagnosis, age, nutritional status, medical history, social history, flap size, and recipient vessels were also reviewed.

The radial forearm flaps were usually taken from the nondominant hand after Allen's test confirmed collateral flow.
The superficial temporal vessels were also palpated and assessed with Doppler bilaterally to determine the best place for inset keeping in mind previous scars from operations, radiation, and/or infections to select the best side for vessel dissections. The flap was first de-epithelialized prior to elevation [Figure 1]. The neurosurgical team gained access to the anterior skull base and debrided any non-viable tissue, including infected and devascularized bone, as necessary [Figure 2]. Most often, the superficial temporal vessels were used and dissected proximally until encountering a curvature

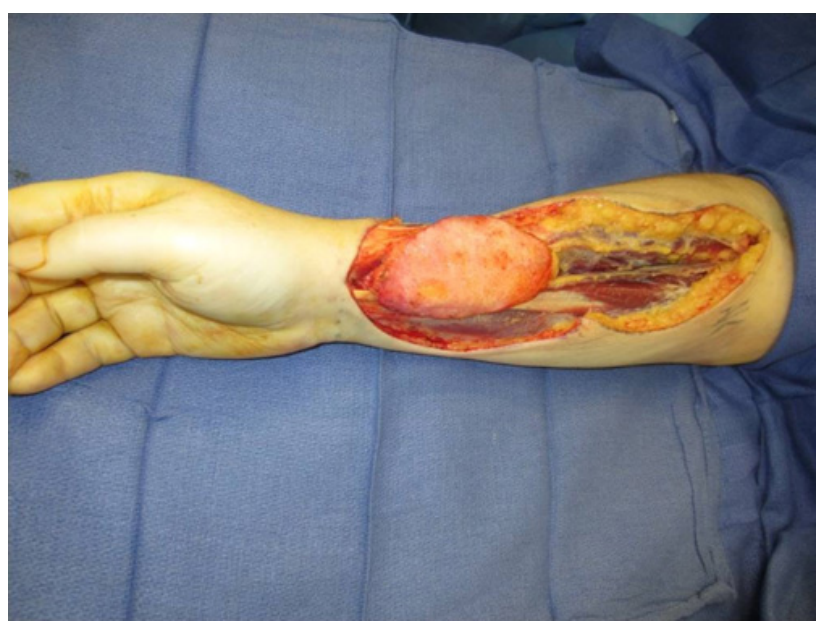

Figure 1: Radial forearm flap de-epithelialized and raised in this left-hand dominate patient

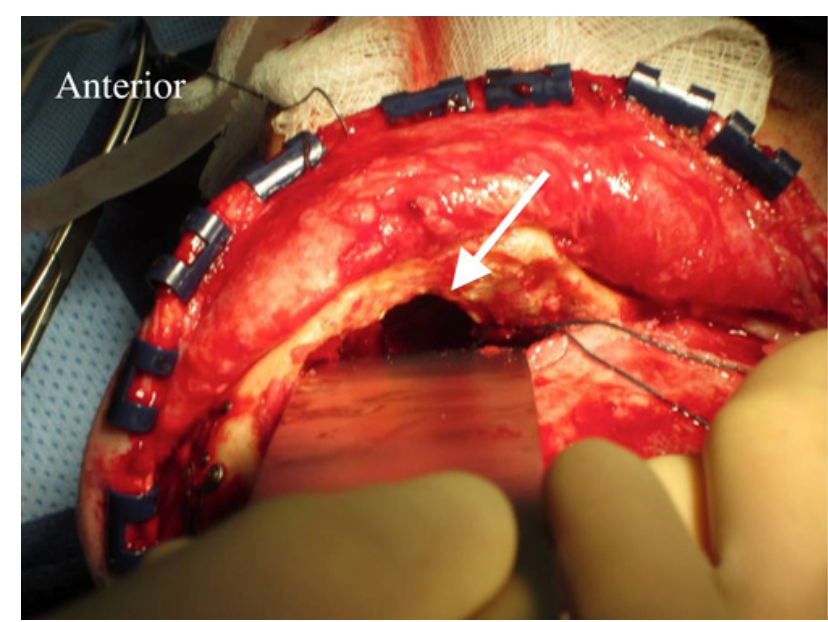

Figure 2: Anterior skull base defect after debridement. Arrow denotes the defect

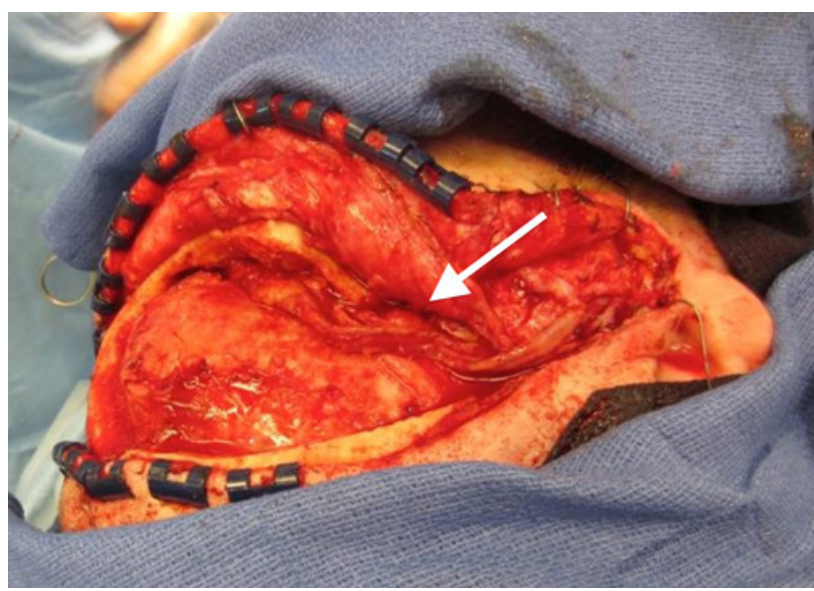

Figure 3: Radial forearm free flap filling the anterior skull base defect. Arrow denotes the pedicle 
of the vessels where they dive deep; the more proximal area of the vessels were less damaged from previous radiation. Using the microscope, the recipient vessels were dissected free and prepared for microvascular anastomosis. The radial artery was hand-sewn to the superficial temporal artery with interrupted 9-0 nylon suture and a venous coupler was used for the venous anastomosis. The flap was then introduced into the defect to ensure adequate filling of the dead space [Figure 3]. Skin was closed primarily over the anastomosis. The donor site was first reduced in size by bringing in the tissue flaps and suturing directly to the deeper structures in the forearm, which allowed for a smaller skin graft to be taken. The forearm was then splinted to protect the skin graft. We did not use intracranial monitoring devices or drains. Patients were monitored in the surgical intensive care unit for three days with Doppler checks distal to the anastomosis every hour.

All research was reviewed and approved by the University of California Irvine Office of Research Institutional Review Board (HS\# 2013-9374).

\section{RESULTS}

All of the patients with anterior skull base defects were males, between the ages of 51 to 63 years. Three of the patients had prior operative interventions performed for malignancy involving the anterior skull base, while the fourth patient had undergone repeated craniotomies for recurrent frontal sinus mucoceles. Although all patients had a normal or near-normal body mass index (range 20.6-26.7), most also had suboptimal nutrition status with an albumin below $3.0 \mathrm{~g} / \mathrm{dL}$. Half of the patients had a remote smoking history, and all but one had a prior diagnosis of diabetes requiring control of hyperglycemia [Table 1].

All 4 patients had prior surgical intervention $(n=4)$, including pericranial flaps, but no patient had a previous free tissue transfer. In addition to surgically altered anatomy, all patients had wound beds further complicated by a combination of recurrent infection $(n=3)$, radiation $(n=2)$, or persistent CSF leak $(n=1)$. In three patients the recipient vessels were the superficial temporal artery and vein. The facial artery and a branch of the external jugular vein were used for anastomosis in one patient. The average total hospital stay was 22.5 days (range 5-38) and average post operative stay was 16 days (range 4-27) [Table 2].

Infection was the most common postoperative complication, affecting three patients $(75 \%)$ and requiring surgical debridement and/or drainage in two. These affected the same patients who had recurrent infections prior to the RFFF coverage. Patient 1 presented with chronic osteomyelitis which was discovered at the time of the RFFF surgery. The patient later developed a CSF leak with an epidural abscess and a wound breakdown at the craniotomy site, requiring drainage and repair, respectively. Patient 3 presented initially with recurrent abscesses, and although postoperatively the patient developed bacteremia, this resolved with IV antibiotics, and there has been no abscess recurrence at ten months follow up. Patient 4 developed a subgaleal infection requiring washout, and a subdural empyema requiring drainage, but his reconstruction remained free of infection at 22 months follow up. Importantly, despite these infective complications, no patients required reoperation on the flap.

All flaps were viable at the conclusion of the study as demonstrated by Doppler flow, and were successful based on clinical exam. Only one patient had a donor site morbidity, which resolved with Integra placement (LifeSciences, Plainsboro, New Jersey), combined with sub-atmospheric pressure therapy. No other major donor site morbidity was noted.

\section{DISCUSSION}

Anterior skull base defects are complex surgical problems and further they are associated with patients who have many comorbidities. They are prone to re-hospitalization and repeated neurosurgical operations given their high risk for life-threatening complications, including

Table 1: Patient demographics

\begin{tabular}{ccccc}
\hline Patient & Age, years & BMI & Albumin & Co-morbidities \\
\hline 1 & 51 & 23.2 & 2.6 & CVA, seizures \\
2 & 62 & 20.6 & 2.3 & Diabetes, hypertension, hyperlipidemia \\
3 & 61 & 26.7 & Not available & Diabetes \\
4 & 63 & 22.2 & 2.4 & Diabetes, hypertension, hyperlipidemia \\
\hline
\end{tabular}

BMI: body mass index; CVA: cerebrovascular accident

Table 2: Patient outcomes following reconstruction of anterior skull base with radial forearm free tissue transfer

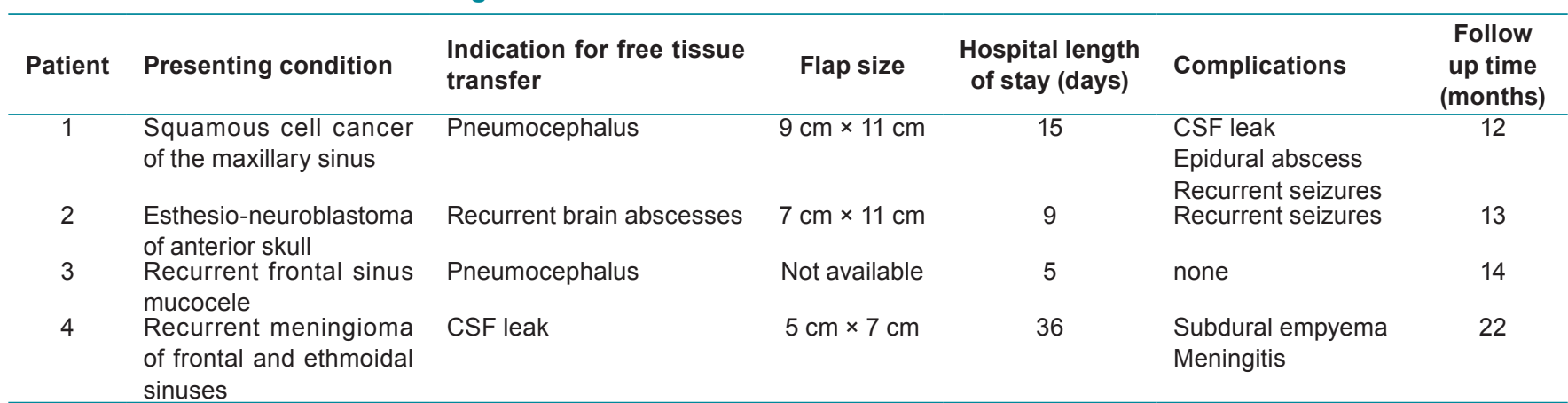

CSF: cerebrospinal fluid 
Table 3: Free tissue transfer alternatives for reconstruction of anterior skull base defects

\begin{tabular}{|c|c|c|}
\hline & Benefits & Disadvantages \\
\hline Radial forearm free flap & $\begin{array}{l}\text { Versatile, reliable donor site anatomy, } \\
\text { long pedicle length, size is appropriate } \\
\text { for most anterior skull base defects }\end{array}$ & $\begin{array}{l}\text { Visible donor site scar. Cannot cover very } \\
\text { large skull base defects. Shorter hospital stays } \\
\text { compared to other free tissue transfers }\end{array}$ \\
\hline Latissimus dorsi muscle free flap & $\begin{array}{l}\text { Consistent vascular pedicle and its } \\
\text { large muscle }\end{array}$ & $\begin{array}{l}\text { Larger donor site defect, greater risk of seroma, } \\
\text { may result in redundant bulky tissue in an anterior } \\
\text { skull base defect }\end{array}$ \\
\hline Vertical rectus abdominis muscle free flap & $\begin{array}{l}\text { Consistent vascular pedicle and its } \\
\text { large muscle }\end{array}$ & $\begin{array}{l}\text { Larger donor site defect, may result in redundant } \\
\text { bulky tissue in an anterior skull base defect }\end{array}$ \\
\hline Serratus anterior muscle free flap & Longer pedicle, versatile size & Can only reliably cover small skull defects \\
\hline Temporoparietal fascial flaps & $\begin{array}{l}\text { Thin and pliable, can be tailored to fit } \\
\text { many defect sizes }\end{array}$ & $\begin{array}{l}\text { May not provide long-term durable coverage. Less } \\
\text { able to obliterate dead space. Limited rotation, can } \\
\text { only provide coverage for anterior defects }\end{array}$ \\
\hline Omental free flap & $\begin{array}{l}\text { Minimal donor site scar, can be tailored } \\
\text { to fit many defect sizes }\end{array}$ & $\begin{array}{l}\text { Can thin over time and may not provide long-term } \\
\text { durable coverage }\end{array}$ \\
\hline Pedicled trapezius flap & $\begin{array}{l}\text { Less complex operation without risk of } \\
\text { vascular anastomoses }\end{array}$ & $\begin{array}{l}\text { Only appropriate for low or inferior defects; pedicle } \\
\text { length is limited }\end{array}$ \\
\hline Pedicled latissimus dorsi & $\begin{array}{l}\text { Less complex operation without risk of } \\
\text { vascular anastomoses }\end{array}$ & $\begin{array}{l}\text { Only appropriate for low or inferior defects; pedicle } \\
\text { length is limited }\end{array}$ \\
\hline
\end{tabular}

meningitis, persistent CSF leak, herniation of brain tissue, pneumocephalus, encephalitis, and brain abscess..$^{[2,3]}$ Patients with malignant tumors of the anterior skull base are prone to even higher rates of complication postresection. ${ }^{[17]}$ As described by Bentz et al., ${ }^{[4]}$ even in patients without confounding complications, the 5-year disease specific survival rate for patients undergoing anterior skull base resection for malignancy is $57 \%$. Those patients with anterior skull base defects whose courses are complicated by prior surgical intervention, radiation, chronic infection, or fistula formation are at even greater risk for death and complications, and often suffer extended hospitalization and repetitive attempts at surgical correction. ${ }^{[2]}$

The impact of prior treatment on overall survival of these complicated patients is significant. As noted by Jackson et al. ${ }^{[18]}$ in a series of 155 patients with tumors affecting the anterior skull base (malignant and non-malignant), survival was $85 \%$ for patients with no prior treatments, but only $48 \%$ for patients with prior intervention. Dos Santos et al. ${ }^{[19]}$ reported in a review of 81 patients who underwent skull base surgery that prior surgical treatment was a pre-operative factor that affected survival significantly. As reported by Teknos et al., ${ }^{[1]}$ patients with skull base defects who have received prior radiation have a significant increase in hospital stay, with an average stay of 17.7 days versus 12.4 days in un-radiated patients. It is therefore important to choose the treatment with the highest chance of success, whether it is the initial repair or a revision of previous failed operations. With this goal, the reliable and well-vascularized RFFF is a reasonable treatment for correction of anterior skull base defects in complex wound beds, especially those weakened by prior interventions. ${ }^{[20]}$

The RFFF is robust, predictable, and well-vascularized, yet lacks the bulkiness of muscle or myocutaneous flaps and is able to fill dimensionally intricate spaces. Compared to other pedicled or free tissue transfers, the radial forearm free flap's reliability and predictability make it an excellent option for infected, radiated buried anterior skull base reconstruction in complex patients who have received previous treatment [Table 3]. Our patients presented with prior surgical intervention $(n=4)$, recurrent infection $(n=3)$, radiation $(n=2)$, persistent CSF leak $(n=1)$, or a combination of these. In our experience with these complex patients with prior therapeutic interventions, we demonstrate improved outcomes compared to previously published results, including $100 \%$ flap survival. For example, we noted an average post operative hospital stay of 16 days (range 4-37), compared to an average hospital stay of 26.4 days reported previously in the literature for cranial base reconstruction with free tissue transfer. ${ }^{[17]}$ To maximize the quality of life of patients with anterior skull base defects, it is essential to minimize their time spent in the hospital and minimize or eliminate the need for any further operations. To this end, we feel that anterior skull base reconstruction with the wellvascularized and highly reliable RFFF is an excellent option for the ill or complex patient who has received prior anterior skull base radiation or surgical intervention.

This case series demonstrates in four patients the successful reconstruction of anterior skull base with radial forearm free tissue transfer. Our flaps were successful in damaged, inhospitable wound beds and the authors are confident that this should be considered as an early reconstructive option in this patient population. Debridement of infected tissue is of upmost importance in these patients, Weber et al. ${ }^{[11]}$ described flap loss secondary to purulent material found at the time of initial free tissue transfer which persisted and occluded the pedicle after one week, despite aggressive antibiotic usage. Califano et al. ${ }^{[2]}$ reported a lower complication rate with free tissue transfer when compared to local flaps, even with more complex resections occurring in the free tissue transfer group. He further reported major complications with $35 \%$ of local tissue transfer and only $31 \%$ with free tissue transfer. ${ }^{[2]}$ This data combined with our experience with the RFFF suggests that free tissue transfer is a reasonable first choice reconstructive option in anterior skull base defects. Due to the moderate success of local flaps, it is reasonable to utilize these flaps before resorting to a RFFF, since they also do not prevent later anastomosing the radial artery to the superficial temporal artery. For secondary reconstruction or salvage operations, the RFFF should be considered after local flaps or other interventions have failed. 
It is important for the plastic surgeon to have a familiarity with anterior skull base defects and the reconstructive possibilities. Fortunately, this defect is not seen everyday, but this means further case series will need to be conducted in order to amass statistically significant data for radial forearm free tissue transfer to anterior skull base defects.

In conclusion, patients with skull base defects are inherently at risk for post-surgical complications. The RFFF is a reliable reconstructive option with the aim of reducing repeat neurosurgical operations and extended hospitalizations. Due to the authors' success with the use of the RFFF, we suggest considering this flap as an early option for reconstruction of anterior skull base defects in those complex patients that have received prior radiation or failed other interventions for soft tissue coverage.

\section{Financial support and sponsorship} Nil.

\section{Conflicts of interest}

There are no conflicts of interest.

\section{REFERENCES}

I. Teknos TN, Smith JC, Day TA, Netterville JL, Burkey BB. Microvascular free tissue transfer in reconstructing skull base defects: lessons learned. Laryngoscope 2002; I I2: 1871-6.

2. Califano J, Coraeiro PG, Disa J], Hidalgo DA, DuMornay W, Bilsky MH, Gutin $\mathrm{PH}$, Shah JP, Kraus DH.Anterior cranial base reconstruction using free tissue transfer: changing trends. Head Neck 2003;25:89-96.

3. Ganly I, Patel SG, Singh B, Kraus DH, Cantu G, Fliss DM, Kowalski LP, Snyderman C, Shah JP. Craniofacial resection for malignant tumors involving the skull base in the elderly: an international collaborative study. Cancer 201 I; I 7:563-7I.

4. Bentz BG, Bilsky MH, Shah JP, Kraus D. Anterior skull base surgery for malignant tumors: a multivariate analysis of 27 years of experience. Head Neck 2003;25:5 I5-20.

5. Ketcham AS, Hoye RC, Van Buren JM, Johnson RH, Smith RR. Complications of intracranial facial resection for tumors of the paranasal sinuses. Am J Surg 1966; | 12:591-6

6. Kadlub N, Shin JH, Ross DA, Della Torre T,Ansari E, Persing JA, Ariyan S. Use of the external pectoralis myocutaneous major flap in anterior base skull reconstruction. Int J Oral Maxillofac Surg 2013;42:453-7.

7. Scher RL, Cantrell RW.Anterior skull base reconstruction with the pericranial flap after craniofacial resection. Ear Nose Throat J 1992;71:2 I0-2, 2I5-7.

8. Costa H, Cerejo A, Baptista A,Vaz R, Gonçalves M, Guimarães A,Amarante J, Cruz C, Guimarães F.The galea frontalis myofascial flap in anterior fossa CSF leaks. Br J Plast Surg 1993;46:503-7.

9. Neligan PC, Mulholland S, Irish J, Gullane PJ, Boyd JB, Gentili F, Brown D, Freeman J. Flap selection in cranial base reconstruction. Plast Reconstr Surg 1996;98:1159-66; discussion II67-8.

10. Hadad G, Bassagasteguy L, Carrau RL, Mataza JC, Kassam A, Snyderman $\mathrm{CH}$, Mintz A. A novel reconstructive technique after endoscopic expanded endonasal approaches: vascular pedicle nasoseptal flap. Laryngoscope 2006; |16:1882-6.

II. Weber SM, Kim JH, Wax MK. Role of free tissue transfer in skull base reconstruction. Otolaryngol Head Neck Surg 2007; I36:9I4-9.

12. Largo RD, Schaefer DJ, Krueger J, Harschnitz O, Zimmerer S, Jaquiéry C, Haug MD, Mariani L, Kunz C. Intracranial application of free fasciocutaneous flaps in a novel sandwich technique for skull base reconstruction. Int J Oral Maxillofac Surg 201 I;40:931-7.

13. Biron VL, Gross M, Broad R, Seikaly H,Wright ED. Radial forearm free flap with titanium mesh sandwich reconstruction in complex anterior skull base defects. J Craniofac Surg 2012;23:I763-5.

14. Valentini V, Fabiani F, Nicolai G, Torroni A, Gennaro P, Marianetti TM, lannetti G. Use of microvascular free flaps in the reconstruction of the anterior and middle skull base. J Craniofac Surg 2006; I7:790-6.

15. Chepeha DB, Wang SJ, Marentette LJ, Thompson BG, Prince ME, Teknos TN. Radial forearm free tissue transfer reduces complications in salvage skull base surgery. Otolaryngol Head Neck Surg 2004; I 31:958-63.

16. Burkey BB, Gerek M, Day T. Repair of the persistent cerebrospinal fluid leak with the radial forearm free fascial flap. Laryngoscope 1999;109:1003-6.

17. Ganly I, Patel SG, Singh B, Kraus DH, Bridger PG, Cantu G, Cheesman A, De Sa G, Donald P, Fliss D, Gullane P, Janecka I, Kamata SE, Kowalski LP, Levine P, Medina LR, Pradhan S, Schramm V, Snyderman C, Wei WI, Shah JP. Complications of craniofacial resection for malignant tumors of the skull base: report of an International Collaborative Study. Head Neck 2005;27:445-5 I.

18. Jackson IT, Marsh WR, Hide TA. Treatment of tumors involving the anterior cranial fossa. Head Neck Surg 1984;6:90I-I3.

19. Dos Santos LR, Cernea CR, Brandao LG, Siqueira MG, Vellutini EA, Velazco OP, Cruz OL, Morais-Besteiro J, Freitas CA. Results and prognostic factors in skull base surgery. Am J Surg 1994; 168:48 I-4.

20. Chang DW, Langstein HN, Gupta A, De Monte F, Do KA, Wang X, Robb G. Reconstructive management of cranial base defects after tumor ablation. Plast Reconstr Surg 200 I; 107:1346-55; discussion 1356-7. 